\title{
Prediction of Intraoperative Hypotension in Full Term Parturients Planned for Elective Caesarean Section with the Help of Supine Stress Test and to Find out Applicability of Supine Stress Test
}

\author{
Vivek Tyagi', Asad Mohammad ${ }^{2}$, Navab Singh ${ }^{3}$ \\ ${ }^{1}$ Assistant Professor, Department of Anaesthesia, Mulayam Singh Yadav Medical College and Hospital, Naal Pur, Distt- Meerut, UP, Pin 245206 , \\ ${ }^{2}$ Associate Professor, Department of Anaesthesia, Muzaffarnagar Medical College and Hospital, Muzaffarnagar, Uttar Pradesh, India. ${ }^{3}$ Associate \\ Professor, Department of Anaesthesia, SMMH Medical College, Saharanpur, 247001.
}

\section{Abstract}

Background: The patients those have tendency to develop supine hypotension syndrome during advance pregnancy also lands in intraoperative hypotension after spinal anaesthesia and this can be predicted in advance with preoperative use of Supine Stress Test. Subjects and Methods: 120 full term parturients with singleton pregnancy planned for elective caesarean section under spinal anaesthesia subjected to Supine Stress Test in preoperative period. Results: Parturients those were positive for Supine Stress Test in preoperative period, significantly land in hypotension during caesarean section. Intraoperative hypotension managed with Inj Ephedrine and fluid. Conclusion: Supine Stress Test is an important tool in predicting intraoperative hypotension in parturients under going elective caesarean section.

Keywords: Supine hypotension syndrome, Supine Stress Test (SST).

Corresponding Author: Dr. Asad Mohammad, Associate Professor, Department of Anaesthesia, Muzaffarnagar Medical College and Hospital, Muzaffarnagar, Uttar Pradesh, India.

Received: May 2019

Accepted: June 2019

\section{Introduction}

Patient position is a factor when measuring blood pressure in parturient. Aortocaval compression by the gravid uterus can have significant impact on both the mother and the fetus. Patient position plays a significant role in its occurrence. Kerr et al. (1964) demonstrated complete obstruction of the inferior vena cava in 10 out of 12 subjects in the supine position. ${ }^{[1]}$ This is referred as supine hypotension syndrome of pregnancy and is induced by compression of inferior caval vein by the enlarged uterus and occurs when the cardiovascular system is unable to compensate for a fall in venous return. It occurs in approximately $8 \%$ of pregnant women at term. ${ }^{[2]}$ Greater number may develop as asymptomatic variety of this syndrome in supine position. ${ }^{[3]}$ The hypotensive effect of spinal anaesthesia per se may be aggravated in a significant number of term parturients.

KinseIla S M et al. (1996) postulated that "if parturients, prone to develop symptomatic or asymptomatic caval compression in supine position could be identified before delivery, this might be a useful method of predicting hypotension during caesarean section under spinal anaesthesia. Indeed, preoperative Supine Stress Tests (SST) before elective caesarean section under spinal anaesthesia have in some studies been shown to predict severe systolic hypotension with reasonable accuracy." ${ }^{[4]}$ Other methods that have been used to predict hypotension in obstetric patients include non-invasive measurement of systemic vascular resistance index, ${ }^{[5]}$ baseline heart rate measurement and analysis of heart rate variability. ${ }^{[6]}$ Chamchad et al. (2004), in their study, evaluated whether point correlation dimension (PD2), a measure of heart rate variability, can predict hypotension accompanying spinal anaesthesia for caesarean delivery Frolich MA and Caton D (2002) concluded that baseline heart rate may predict hypotension after spinal anaesthesia in prehydrated obstetrical patients. ${ }^{[7]}$ Patients with higher baseline heart rate, possibly reflecting a higher sympathetic tone needs statistically significant increase in ephedrine consumption after spinal anaesthesia. ${ }^{[8]}$

Recently treatment of maternal hypotension has changed from prophylactic intravenous hydration before spinal anaesthesia and administration of ephedrine, towards co hydrations with crystalloids and aggressive use of phenylephrine. ${ }^{[9,10]}$

Present study carried out in full term parturients planned for elective caesarean section in which a preoperative Supine Stress Test applied few hrs before caesarean section. Predictability of Supine Stress Test as an advance predictor of Intra operative hypotension is assessed.

\section{Subjects and Methods}


0

Healthy parturients with full term normal singleton pregnancies presenting for elective caesarean section were included in this study. After obtaining permission from ethical committee, parturients were examined thoroughly and subjected to routine investigation including hemoglobin, TLC, DLC, RBS, blood urea, serum creatinine and urine examination for both routine and microscopy. Informed and routine consent was taken from each and every patient.

\section{Selection of Cases Was Made on the Following Criteria:-} Inclusion criteria

- Parturients both primi and multigravida with normal singleton pregnancy belonging to ASA grade I and II.

- Gestational age of fetus between 37 to 42 completed weeks

\section{Exclusion criteria}

- Any contraindication to subarachnoid block including patient refusal.

- Fetal heart rate more than 160 bpm or less than 100 bpm

- Patients belonging to ASA grade III and above

A detailed obstetrical examination was also done and findings were recorded.

\section{Preoperative Supine Stress Test:-}

A Supine Stress Test (SST) was performed at least 6 hours before caesarean section in examination room, just adjacent to operation theatre where Non Stress Test (NST) was applied and continuous fetal heart rate tracing were obtained to rule out fetal distress during any part of the test. The patient was allowed to rest in the left lateral position for 10 min before study. Blood pressure was recorded with an automatic non-invasive blood pressure monitor (Model HEM-7111). The blood pressure cuff was placed on left arm to minimize the hydrostatic effect from the lateral position. With the subject lying in the full left lateral position blood pressure and heart rate were measured once a minute for 3 minute. The average values of these measurements were used as a baseline. Measurements were continued every minute for $10 \mathrm{~min}$ with the patient lying supine, with one pillow under the head, and then again it left lateral position for another $5 \mathrm{~min}$. During the supine part of the test it was noticed whether the patient crossed her legs or flexed her hips and knees. The patient was urged to tell about any symptoms that developed when lying supine. She was allowed to turn to her left if she needed to change position.

The SST was considered positive if one or more of the following criteria was/were fulfilled.

1. Increase in maternal heart rate $>10$ beats/min compared to baseline during at least two consecutive measurements.

2. Decrease systolic arterial blood pressure $>15 \mathrm{~mm} \mathrm{Hg}$ compared to baseline during at least two consecutive minute measurements.

3. Signs related to supine position (hip flexion, crossing of legs).

4. Symptoms related to the supine position (e.g. Nausea / vomiting/dizziness) requiring a change in position.

In addition to the SST the subjects will be asked to answer the following two questions:

1. During the last three months of pregnancy have you experienced nausea, vomiting, dizziness or faintness when lying supine? (Yes / No)

2. During last three months of pregnancy have you been able to sleep in the supine position? (Yes/ $\mathrm{No} /$ don't know).

A total of 140 parturients were subjected to Supine Stress Test. On the basis of results of Supine Stress Test, out of 140 parturients, 120 were selected with each group consisting of 60 patients in this study.

- Group A - patients with SST +ve

- Group B - patients with SST-ve

\section{Advice to Patient}

Parturients were fasted for 6-8 hrs and received no medication preoperatively.

\section{Anaesthetic technique:}

After shifting to the operation theatre, each patient was examined thoroughly. Blood pressure, pulse rate, respiratory rate and $\mathrm{SpO} 2$ were recorded. Fetal heart sound was recorded by fetoscope. IV line was established with 18 gauge cannula and patients were infused with $10 \mathrm{ml} / \mathrm{kg} / \mathrm{hr}$ with Ringer's lactate solution. $2.0 \mathrm{ml}$ of $0.5 \%$ bupivacaine heavy $(10 \mathrm{mg})$ and $0.20 \mathrm{ml}$ of fentanyl $(10 \mu \mathrm{g})$ were loaded in a $5 \mathrm{ml}$ syringe. The spinous process and iliac crest were identified and marked. L3-L4 interspace was palpated in sitting position and a 25 gauze Quincke's needle was introduced. When free flow of CSF was observed, preloaded drug solution was injected into the subarachnoid space. The same dose was used for all subjects regardless of height. The spinal needle was withdrawn and the puncture site was sealed with sterile dressing. Immediately after the injection, the patient was positioned supine with slightly flexed hips and knees and with a combination of wedge under right hip allowing for a maximal caval relief (at least 30o in all patients). Supplemental O2 was administered through a venti mask at 3-4 lit/min.

Pulse rate, blood pressure, respiratory rate and $\mathrm{SpO} 2$ were observed and recorded.

In event of hypotension i.e. systolic blood pressure less than $90 \mathrm{mmHg}$ or fall of more than $20 \%$ of baseline, $5 \mathrm{mg}$ of ephedrine was given. If the systolic blood pressure dropped further below $90 \mathrm{mmHg}$, the drug dose was repeated once a minute as long as pressure stayed below $90 \mathrm{mmHg}$. Rescue ephedrine or phenylephrine was given in the same dose and with the same dose interval of the patient developed discomfort associated with a decrease in SBP of at least $20 \%$ from baseline even if it was above $90 \mathrm{mmHg}$. All patients receiving at least one dose of ephedrine were thus considered hypotensive.

The surgical technique was uniform in all the patients and included exteriorization of the uterus. $10 \mathrm{IU}$ of oxytocin was given by IV infusion after delivery of baby and clamping of umblical cord.

\section{Results}

A total of 120 parturients were subjected to Supine Stress Test admitted for planned elective caesarean delivery under 
0

spinal anaesthesia. They included primi as well as multigravida.

\section{The Study Groups:-}

On the basis of results of SST, patients were divided into two groups and 120 patients out of 140 were randomly selected,

1. Group A- Patients with SST+ve

2. Group B - Patients with SST-ve

After completion of study, data were categorized and analyzed and following observations were made.

Table 1: Result of Supine Stress Test on the basis of criteria

\begin{tabular}{|l|l|}
\hline Supine Stress Test criterion & No. of parturients \\
\hline Heart rate criterion only & 33 \\
\hline BP criterion only & 0 \\
\hline Signs related criterion only & 3 \\
\hline Symptoms related criterion only & 2 \\
\hline
\end{tabular}

Table 2: Result of Supine Stress Test on the basis of criteria

\begin{tabular}{|l|l|l|l|}
\hline & $\begin{array}{l}\text { Heart rate } \\
\text { criterion }\end{array}$ & BP criterion & $\begin{array}{l}\text { Heart rate+BP } \\
\text { criteria }\end{array}$ \\
\hline $\begin{array}{l}\text { Signs related } \\
\text { criterion }\end{array}$ & 6 & 3 & 0 \\
\hline $\begin{array}{l}\text { Symptoms related } \\
\text { criterion }\end{array}$ & 6 & 0 & 4 \\
\hline BP criterion & 3 & -- & -- \\
\hline
\end{tabular}

Table 3: Demographic data

\begin{tabular}{|c|c|c|c|c|c|c|c|c|}
\hline \multicolumn{3}{|c|}{$\begin{array}{l}\text { Distribution of } \\
\text { patients according } \\
\text { to age (years) }\end{array}$} & \multicolumn{3}{|c|}{$\begin{array}{l}\text { Distribution of } \\
\text { patients according } \\
\text { to weight }(\mathrm{kgs})\end{array}$} & \multicolumn{3}{|c|}{$\begin{array}{l}\text { Distribution of } \\
\text { patients according to } \\
\text { height }(\mathrm{cms})\end{array}$} \\
\hline & A & B & & A & B & & A & B \\
\hline $\begin{array}{l}18- \\
21\end{array}$ & 15 & 15 & $\begin{array}{l}45- \\
55\end{array}$ & 5 & 5 & $\begin{array}{l}131- \\
140\end{array}$ & 8 & 7 \\
\hline $\begin{array}{l}22- \\
25\end{array}$ & 21 & 17 & $\begin{array}{l}56- \\
65\end{array}$ & 39 & 30 & $\begin{array}{l}141- \\
150\end{array}$ & 25 & 23 \\
\hline $\begin{array}{l}26- \\
29\end{array}$ & 12 & 19 & $\begin{array}{l}65- \\
75\end{array}$ & 13 & 18 & $\begin{array}{l}151- \\
160\end{array}$ & 22 & 24 \\
\hline $\begin{array}{l}30- \\
33\end{array}$ & 11 & 9 & $\begin{array}{l}76- \\
85\end{array}$ & 3 & 7 & $\begin{array}{l}161- \\
170\end{array}$ & 5 & 6 \\
\hline $\begin{array}{l}\text { Mea } \\
\mathrm{n} \pm \mathrm{S} \\
\mathrm{D}\end{array}$ & $\begin{array}{l}24.3 \\
3 \pm 4 \\
33\end{array}$ & $\begin{array}{l}24.9 \\
6 \pm 4 \\
60\end{array}$ & $\begin{array}{l}\text { Mea } \\
\mathrm{n} \pm \mathrm{S} \\
\mathrm{D}\end{array}$ & $\begin{array}{l}62.9 \\
0 \pm 6 . \\
29\end{array}$ & $\begin{array}{l}64.9 \\
6 \pm 7 \\
29\end{array}$ & $\begin{array}{l}\text { Mea } \\
\mathrm{n} \pm \mathrm{S} \\
\mathrm{D}\end{array}$ & $\begin{array}{l}149.0 \\
0 \pm 7.9 \\
5\end{array}$ & $\begin{array}{l}151.0 \\
6 \pm 6.9 \\
4\end{array}$ \\
\hline
\end{tabular}

Above table shows that majority of patients in both two, A and $\mathrm{B}$ groups have no significant difference between age, weight and height related parameters. $(\mathrm{p}>0.05)$.

Table 4: Change in mean pulse rate (per min) at different time intervals

\begin{tabular}{|c|c|c|}
\hline & Group A & Group B \\
\hline Pre-op & $96.10 \pm 5.35$ & $93.76 \pm 6.43$ \\
\hline Just after block & $96.53 \pm 7.95$ & $96.13 \pm 5.00$ \\
\hline At $5 \mathrm{~min}$ & $82.03 \pm 5.35$ & $83.23 \pm 8.25$ \\
\hline At $10 \mathrm{~min}$ & $78.96 \pm 12.07$ & $76.06 \pm 9.16$ \\
\hline At $15 \mathrm{~min}$ & $91.00 \pm 15.15$ & $87.46 \pm 11.99$ \\
\hline At $20 \mathrm{~min}$ & $99.53 \pm 15.78$ & $95.23 \pm 12.95$ \\
\hline At $30 \mathrm{~min}$ & $101.06 \pm 11.83$ & $98.66 \pm 10.80$ \\
\hline At $40 \mathrm{~min}$ & $98.76 \pm 8.15$ & $94.36 \pm 7.64$ \\
\hline At $50 \mathrm{~min}$ & $95.96 \pm 6.12$ & $92.55 \pm 5.16$ \\
\hline At $60 \mathrm{~min}$ & $93.47 \pm 5.71$ & $92.05 \pm 5.97$ \\
\hline
\end{tabular}

No significant difference in heart rates in two groups, A and $B$ at same time interval frame. $(p>0.05)$.

Pattern of decrease in pulse rates were identical in both groups with time. Pulse rates in both groups at 5 and 10 minutes were statistically significant when compared to preoperative values $(\mathrm{p}<0.05)$.

When compared in different groups in the same frame of time, following observation was made-In between group A and $\mathrm{B}$, no significant changes in pulse rates were observed $(\mathrm{p}>0.05)$.

Table 5: Change in SBP $(\mathrm{mmHg})$ at different time interval

\begin{tabular}{|l|l|l|}
\hline & A & B \\
\hline Pre-op & $115.16 \pm 8.83$ & $115.83 \pm 7.23$ \\
\hline Just after block & $108.56 \pm 11.11$ & $111.00 \pm 7.44$ \\
\hline At 5 min & $92.64 \pm 10.23$ & $98.23 \pm 8.79$ \\
\hline At 10 min & $90.96 \pm 6.36$ & $100.93 \pm 6.41$ \\
\hline At 15 min & $98.70 \pm 6.02$ & $110.70 \pm 6.54$ \\
\hline At 20 min & $106.3 \pm 7.28$ & $108.43 \pm 6.06$ \\
\hline At 30 min & $111.53 \pm 5.65$ & $116.70 \pm 6.01$ \\
\hline At 40 min & $112.80 \pm 5.87$ & $114.33 \pm 4.92$ \\
\hline At 50 min & $115.12 \pm 4.78$ & $120.11 \pm 4.70$ \\
\hline At 60 min & $118.15 \pm 4.23$ & $116.35 \pm 4.70$ \\
\hline
\end{tabular}

[Table 5] shows the mean systolic blood pressure in both groups.

There was no significant difference in mean systolic blood pressure in both groups before giving the block. Max.fall in $\mathrm{BP}$ occurred at around $10 \mathrm{~min}$ in both groups which was statistically significant $(\mathrm{p}<0.05)$ in comparison to preoperative values i.e. more numerically fall in Group A.

Table 6: Change in DBP $(\mathbf{m m H g})$ at different time interval
\begin{tabular}{|l|l|l|}
\hline & A & B \\
\hline Pre-op & $69.96 \pm 6.86$ & $70.23 \pm 5.09$ \\
\hline Just after block & $67.96 \pm 8,52$ & $68.93 \pm 5.63$ \\
\hline At $5 \mathrm{~min}$ & $54.03 \pm 8.58$ & $60.93 \pm 4.81$ \\
\hline At $10 \mathrm{~min}$ & $56.60 \pm 7.14$ & $62.80 \pm 4.64$ \\
\hline At $15 \mathrm{~min}$ & $60.83 \pm 6.28$ & $60.76 \pm 4.82$ \\
\hline At $20 \mathrm{~min}$ & $63.10 \pm 5.76$ & $63.20 \pm 4.33$ \\
\hline At $30 \mathrm{~min}$ & $65.23 \pm 5.48$ & $64.50 \pm 4.93$ \\
\hline At $40 \mathrm{~min}$ & $65.93 \pm 5.55$ & $66.30 \pm 4.92$ \\
\hline At $50 \mathrm{~min}$ & $67.60 \pm 4.54$ & $67.59 \pm 4.74$ \\
\hline At $60 \mathrm{~min}$ & $68.52 \pm 5.02$ & $68.35 \pm 5.63$ \\
\hline
\end{tabular}

[Table 6] shows the mean diastolic blood pressure changes among the groups at different time intervals.

There was no significant difference in mean diastolic blood pressure in all groups before giving the block.

Maximum fall in BP occurred at $10 \mathrm{~min}$ in both groups and was significant in comparison to preoperative values. Fall in $\mathrm{BP}$ is more at 5 and $10 \mathrm{~min}$ in Group A and statistically significant in comparison to Group B.

Table 7: Supine Stress Test vs. intraoperative hypotension

\begin{tabular}{|l|l|l|}
\hline & $\begin{array}{l}\text { Group A } \\
\text { (SST+ve) } \\
\mathbf{n = 6 0}\end{array}$ & $\begin{array}{l}\text { Group B } \\
\text { (SST-ve) } \\
\mathbf{n = 6 0}\end{array}$ \\
\hline Developed hypotension & 38 & 27 \\
\hline Remained normotensive & 22 & 33 \\
\hline
\end{tabular}

[Table 7] shows development of hypotension in Group A (SST+ve) and Group B (SST-ve). More numbers of patients in Group A lands in hypotension in comparison to Group B. Development of hypotension in SST+ve group is statistically significant in comparison to SST-ve group $(\mathrm{p}<0.05)$. 
$\underline{0}$

Table 8: Supine Stress Test \& Ephedrine consumption

\begin{tabular}{|l|l|l|}
\hline & Group A & Group B \\
\hline $\begin{array}{l}\text { Mean Ephedrine consumption } \\
(\mathrm{mg}) \text { Mean } \pm \text { SD }\end{array}$ & $14.25 \pm 5.77$ & $9.64 \pm 3.65$ \\
\hline
\end{tabular}

[Table 8] shows Mean ephedrine consumption was more in Group A (SST+ve) in comparison to Group B (SST-ve) but failed to prove statistically significant $(>0.05)$.

\section{Discussion}

First caesarean delivery using cocaine spinal anaesthesia was performed in UK at Manchester hospital in 1901. ${ }^{[1]}$

General anaesthesia is associated with higher mortality rate in comparison to regional anaesthesia. ${ }^{[12,13]}$

The supine hypotension was described by Hansen in 1942. Its clinical relevance became apparent in 1957 when it was postulated by Holmes as the cause of death in healthy young women during caesarean section under spinal anaesthesia. ${ }^{[14]}$ Maternal hypotension is most notorious complication during caesarean section in pregnant female under spinal anaesthesia which can be predicted in advance by certain parameter in preoperative period. Supine Stress Test is one of them which was used in present study.

120 patients were subjected to Supine Stress Test in preoperative period. Heart rate criterion was positive in 52 patients, hypotension criterion in 10 patients, hip flexion criterion in 12 and symptoms related criterion in 12 patients. Other criteria were also positive in above patients. In respect of positivity of individual criterion, heart rate criterion was positive in 33, hip flexion criterion in 3 and symptoms related criterion in 2 patients. Not even a single individual had hypotension criterion alone. Hypotension criterion was associated with symptoms related criterion in 4 , heart rate criterion in 3 and hip flexion criterion in 3 patients. 6 patients with symptoms related criterion and 6 patients with hip flexion criterion also positive for heart rate criterion.

The definition of a positive Supine Stress Test adhered closely to the definition used in the study by Kinsella and Norris (1996)4. G. Dahlgren and L. Irestedt (2006) also used SST, and SST was positive in about $36 \%$ in their study. 15 In addition to the two criteria for a positive SST (increase in heart rate more than 10 beats/min and/or leg movements) they added a decrease in systolic arterial pressure more than $15 \mathrm{mmHg}$ and symptoms related to the supine position requiring a change in position. 60 out of 140 patients had a positive SST on the basis of above. Thus Supine Stress Test was positive in $42.85 \%$. Incidence of supine hypotension syndrome in pregnancy is about $8 \%$ in the study of Kinsella S M and Lohmann G. (1994)2 while it was $7.14 \%$ in present study when only hypotension criterion was considered which very well corresponds to the study of Dahlgren $G$ and Irestedt L (2006), ${ }^{[15]}$ where 3 patients out of $53(6 \%)$ were positive for hypotension criterion.

\section{Supine Stress Test vs. Intraoperative hypotension}

Hypotension was defined as systolic blood pressure below 90 $\mathrm{mmHg}$. If the patient developed discomfort associated with a decrease in systolic blood pressure of at least $20 \%$ from baseline even if it was above $90 \mathrm{mmHg}$, rescue vasopressor either ephedrine $(5 \mathrm{mg})$ was given. All patients receiving at least one dose of vasopressor were considered hypotensive. In SST +ve group, 38 out of 60 patients developed hypotension in comparison to 27 out of 60 patients in SST ve group. There was statistically significant difference $(p<0.05)$ in two groups in relation to development of hypotension. Thus SST+ve patients were more prone to develop intraoperative hypotension in comparison to SST-ve patients.

Thus SST can be used as a predictor of hypotension after spinal anaesthesia for elective caesarean section. This fact proves the applicability of SST as an advance predictor of hypotension in these patients.

Kinsella SM et al (1996)4 and Dahlgren G et al (2006)15 used Supine Stress Test in advance prediction of hypotension in full term parturients planned for elective caesarean delivery successfully. Dahlgren G. et al (2006) in their study, prediction of hypotension during spinal anaesthesia for caesarean section and its relation to the effect of crystalloid or colloid preload, showed that 15 out of 19 patients in SST+ve and 21 out of 34 patients in SST-ve groups developed intraoperative hypotension. ${ }^{[15]}$

\section{Ephedrine Consumption}

Mean Ephedrine consumption was $14.25 \pm 5.77 \mathrm{mg}$ in SST+ve gp (A1) and 9.64 $\pm 3.65 \mathrm{mg}$ in SST-ve gp (A2). Thus ephedrine consumption was more in SST+ve group in comparison SST-ve gp but failed to prove statistically significance $(\mathrm{p}>0.05)$.

Dahlgren G. et al (2006) showed that ephedrine consumption in SST+ve and SST-ve group were $20.0 \pm 9.7 \mathrm{mg}$ and $6.8 \pm 7.5$ in their study and they were statistically significant. ${ }^{[15]}$

Magalhães E, Govêia CS et al (2009); Ephedrine v ersus phenylephrine: prevention of hypotension during spinal block for caesarean section and effects on the fetus and concluded the mean dose of ephedrine used was $14.8 \pm 3.8 \mathrm{mg}$ and of phenylephrine was $186.7 \pm 52.9 \mu \mathrm{g} .{ }^{[16]}$

\section{Conclusion}

SST+ve group significantly lands into hypotension during intraoperative period. Thus Supine Stress Test is an effective tool to predict intraoperative hypotension preoperatively in a parturient planned for elective caesarean delivery under spinal anaesthesia. Indirect evidence is more Ephedrine consumption in Group A (SST+ve)

\section{References}

1. Kerr MG, Scott DB, Samuel E. Studies in the inferior vena cava in late pregnancy.Br Med j 1964; 1: 532-3.

2. Kinsella S M, Lohmann G. Supine hypotension syndrome. Obstet Gynecol 1994; 83: 774-88

3. Calvin S, Jones O W, Knieriem K, Weinstein L. Oxygen saturation in the supine hypotension syndrome. Obstet Gynecol 1988; 71: 872-7

4. Kinsella S M, Norris M C. Advance prediction of hypotension at caesarean delivery under spinal anaesthesia. Int J Obstet Anesth 1996; $5: 3-7$

5. Ouzounian J G et al. Systemic vascular resistance index determined by thoracic electrical bioimpedance predicts the risk for maternal hypotension during regional anaesthesia for caesarean delivery. Am J Obstet Gynecol 1996; 174: 1019-25

6. Pristley W O, Storer HR. The obstetric memories and contributions of James Y Simpson, Edinburg A and C Black, Vol2; 1856 
0

. Chamchad D et al. Using heart rate variability to stratify risk of obstetric patients undergoing spinal anaesthesia. Anesth Analg 2004; 99: 1818-

8. Frolich M A, Caton D. Baseline heart rate may predict hypotension after spinal anaesthesia in prehydrated obstetrical patients. Can J Anesth 2002; 49: 185-9

9. Dayer R A et al. Crystalloid preload versus rapid crystalloid administration after induction of spinal anaesthesia (coload) for elective caesarean section. Anaesth Intensive Care 2004; 32: 351-7.

10. Ngan kee W D et al. Prevention of hypotension during spinal anaesthesia for caesarean delivery: an effective technique using combination of phenylephrine infusion and crystalloid cohydration. Anesthesiology 2005; 103: 744-50.

11. D Angelo R, Thomas JA : Regional anaesthesia in obstetrics, Handbook of Obstet anaesthesia,2002: 42-67

12. Bassell GM, Marx GF: Anaesthesia related maternal mortality. In : Anaesthesia for obstetrics, 3rd ed. Schnider SM, Levinson G. eds. Baltimore : Williams and Wilkins, 1993 :458-460.

13. Davis AG. Anaesthesia for caesarean section. The potential of regional block. Jr of $\mathrm{Gr} \mathrm{Br}$ and Ireland. Anaesthesia 1982.

14. Medical Memoranda. Supine hypotension syndrome during pregnancy. British Med J 1970; 1: 797-798.

15. G. Dahlgren, L. Irestedt. Prediction of hypotension during spinal anaesthesia for caesarean section and its relation to the effect of crystalloid or colloid preload. Int J Obstet Anesth 2007; 16: 128-134

16. Magalhães E et al. Ephedrine versus phenylephrine: prevention of hypotension during spinal block for caesarean section and effects on the fetus. Rev Bras Anestesiol. 2009 Jan-Feb; 59(1):11-20

Copyright: () the author(s), publisher. Academia Anesthesiologica Internationalis an Official Publication of "Society for Health Care \& Research Development". It is an open-access article distributed under the terms of the Creative Commons Attribution Non-Commercial License, which permits unrestricted non-commercial use, distribution, and reproduction in any medium, provided the original work is properly cited.

How to cite this article: Tyagi V, Mohammad A, Singh N. Prediction of Intraoperative Hypotension in Full Term Parturiens Planned for Elective Caesarean Section with the Help of Supine Stress Test and to Find out Applicability of Supine Stress Test. Acad. Anesthesiol. Int. 2019;4(2):25-29.

DOI: dx.doi.org/10.21276/aan.2019.4.2.7

Source of Support: Nil, Conflict of Interest: None declared. 